\title{
Assessment of root canal morphology of maxillary and mandibular second molars in the Iranian population using CBCT
}

\section{Ocena morfologii kanałów korzeniowych drugich górnych i dolnych zębów trzonowych w populacji irańskiej z wykorzystaniem tomografii stożkowej}

\author{
Zakiyeh Donyavi ${ }^{1, A}$, Abbas Shokri' ${ }^{2, A, D}$, Elham Khoshbin ${ }^{1, E}$, Maryam Khalilil, ${ }^{1, A, B, D-F}$, Javad Faradma ${ }^{3,4, C}$ \\ 1 Department of Endodontics, School of Dentistry, Hamadan University of Medical Sciences, Iran \\ ${ }^{2}$ Dental Implant Research Center, Department of Oral and Maxillofacial Radiology, School of Dentistry, Hamadan University of Medical Sciences, Iran \\ ${ }^{3}$ Modeling of Non-communicable Diseases Research Center, Hamadan University of Medical Sciences, Iran \\ ${ }^{4}$ Department of Biostatistics and Epidemiology, School of Public Health, Hamadan University of Medical Sciences, Iran \\ A - research concept and design; $\mathrm{B}$ - collection and/or assembly of data; $\mathrm{C}$ - data analysis and interpretation; \\ $D$ - writing the article; $E$ - critical revision of the article; $F$ - final approval of the article
}

\section{Address for correspondence}

Maryam Khalili

E-mail: maryamkhalili698@gmail.com

\section{Funding sources}

None declared

Conflict of interest

None declared

\section{Acknowledgements}

This investigation has been approved and financially supported by the Vice-Chancellor for Research and Technology of Hamadan University of Medical Sciences, Iran.

Received on September 3, 2018

Reviewed on November 4, 2018

Accepted on December 18, 2018

Published online on March 29, 2019

Cite as

Donyavi Z, Shokri A, Khoshbin E, Khalili M, Faradmal J. Assessment of root canal morphology of maxillary and mandibular second molars in the Iranian population using CBCT. Dent Med Probl. 2019;56(1):45-51. doi:10.17219/dmp/101783

DOI

$10.17219 / \mathrm{dmp} / 101783$

Copyright

(C) 2019 by Wroclaw Medical University

This is an article distributed under the terms of the

Creative Commons Attribution Non-Commercial License

(http://creativecommons.org/licenses/by-nc-nd/4.0/)

\begin{abstract}
Background. Inability to efficiently clean all root canals due to the complex anatomy of the root canal system is a common cause of endodontic treatment failure.

Objectives. This study aimed to assess the root canal morphology of the maxillary and mandibular second molars using cone-beam computed tomography (CBCT).

Material and methods. This descriptive study evaluated 502 CBCT scans taken in the years 2014-2017. The number of roots and canals, type of canals according to the Vertucci classification, presence of maxillary second molars with 2 palatal roots, and C-shaped canals in the maxillary and mandibular second molars were evaluated on CBCT scans separately by a radiologist and 2 endodontists. The data was analyzed using SPSS via descriptive statistics, Fisher's exact test, the independent samples t-test, and the $x^{2}$ test. All the analyses were performed with a confidence level of $95 \%$.

Results. The majority of the palatal, mesiobuccal and distobuccal roots of the maxillary second molars had 1 single canal of Vertucci type l; $21.5 \%$ of the mesiobuccal roots had a second mesiobuccal canal $(p=0.05)$.

Conclusions. Two-rooted mandibular second molars and 3-rooted maxillary second molars were the most common in our study population. Cone-beam computed tomography as a non-invasive and highly accurate imaging modality is efficacious for the detection of additional roots and C-shaped canals.
\end{abstract}

Key words: cone-beam computed tomography, morphology, root canal

Słowa kluczowe: tomografia stożkowa, morfologia, kanał korzeniowy 


\section{Introduction}

Inability to efficiently clean and treat all root canals due to the complex anatomy of the root canal system is a common cause of failure of non-surgical endodontic treatment. Missing a canal, inadequate knowledge on the morphological and anatomical variations of the root canals and teeth, incorrect interpretation of the angulated radiographs of the respective tooth, inappropriate access cavity design, and inefficient cleaning, shaping or obturation of the root canals are among the main causes of endodontic treatment failure. ${ }^{1}$ Therefore, knowledge of the complex internal morphology of the root canal system is imperative, prior to treatment planning and the commencement of treatment. Also, adequate knowledge of the root canal morphology of all teeth is a prerequisite for successful endodontic treatment. ${ }^{2}$ The molar teeth commonly require endodontic treatment due to the high prevalence of caries. ${ }^{3}$ On the other hand, endodontic treatment of the mandibular teeth is challenging due to the variations in their morphology. ${ }^{4}$ The molar teeth have a wide range of anatomical variations with respect to the number of roots and canals. ${ }^{5}$

Several methods have been employed for the assessment of roots and canals. The clearing and staining technique is among the most commonly used methods for the evaluation of the root canal system. ${ }^{3}$ However, recent studies have used cone-beam computed tomography (CBCT) for this purpose, since this imaging modality enables accurate visualization of details without noise or the superimposition of adjacent structures. ${ }^{6}$

Cone-beam computed tomography has been used in endodontics since the 1990s. The applications of CBCT in endodontics include the assessment of endodontic and non-endodontic pathologies, internal and external root resorption, and anatomical variations of the root canal system. ${ }^{7}$ Cone-beam computed tomography enables 3-dimensional visualization of anatomical structures and pathological lesions, and is a highly valuable modality for this purpose. ${ }^{8}$

Despite the presence of numerous studies on the root and canal morphology of the maxillary and mandibular molars, studies on this topic using CBCT are scarce. Considering the diversity in the anatomical and morphological variations of the tooth roots in different populations and races, and the significance of knowledge on this subject for successful endodontic treatment, this study aimed to assess the root canal morphology of the maxillary and mandibular second molars in the Iranian population using CBCT.

\section{Material and methods}

This descriptive, cross-sectional study was performed on 502 CBCT scans. The CBCT scans belonged to patients who required orthodontic, surgical or implant treatment in the years 2014-2017. The study was approved by the ethics committee of Hamadan University of Medical Sciences, Iran (IR.UMSHA.REC.1396.239).

The inclusion criteria were as follows: high-quality CBCT scans, visualization of the maxillary and mandibular second molars on CBCT scans, absence of restorations and no previous endodontic treatment of the molar teeth, absence of periapical lesions or periodontal ligament widening, absence of internal and external root resorption, and presence of completely formed roots. ${ }^{9}$ All CBCT scans had been obtained with a CRANEX ${ }^{\circledR}$ 3D CBCT system (Soredex, Tuusula, Finland) with $0.2 \mathrm{~mm}$ voxel size and $6 \times 8 \mathrm{~cm}^{2}$ field of view. All images were evaluated in axial, coronal and sagittal sections using OnDemand3D ${ }^{\mathrm{TM}}$ Dental software (Cybermed, Inc., Seoul, South Korea). To assess the number of roots and types of canals, the cross-sectional images were reconstructed along the parasagittal and paracoronal planes so that the path and morphology of the canals could be easily evaluated and analyzed from the buccolingual and mesiodistal directions. The slice thickness was $0.5 \mathrm{~mm}$ and the slice interval was $1 \mathrm{~mm}$ in the parasagittal and paracoronal image reconstructions.

The CBCT scans of the teeth that met the eligibility criteria were evaluated in terms of the number of roots (Fig. 1) and types of canals in each root according to the Vertucci classification ${ }^{6}$ :

- type I: 1 single canal from the pulp chamber to the apex; - type II: 2 separate canals exiting the pulp chamber, but merging close to the apex;

- type III: 1 canal exiting the pulp chamber and branching into 2 canals that eventually merge;

- type IV: 2 separate canals from the pulp chamber to the apex;

- type V: 1 canal exiting the pulp chamber and branching into 2 canals that eventually lead to 2 separate apical foramina;

- type VI: 2 separate canals exiting the pulp chamber, merging at the mid-root, branching again, and ending at 2 apical foramina;

- type VII: 1 canal exiting the pulp chamber, branching into 2 canals at the mid-root that merge again and branch again ending at 2 apical foramina;

- type VIII: 3 separate canals from the pulp chamber to the apex (Fig. 2).

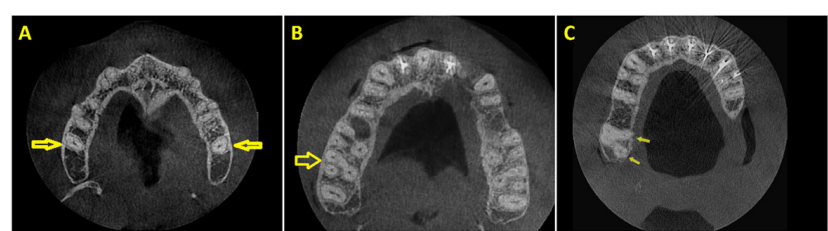

Fig. 1. A: Axial cone-beam computed tomography (CBCT) section of a single-rooted maxillary second molar; $\mathrm{B}$ : Axial CBCT section of a maxillary second molar with 3 roots and 3 canals; C: Axial CBCT section of a maxillary second molar with 2 palatal roots 


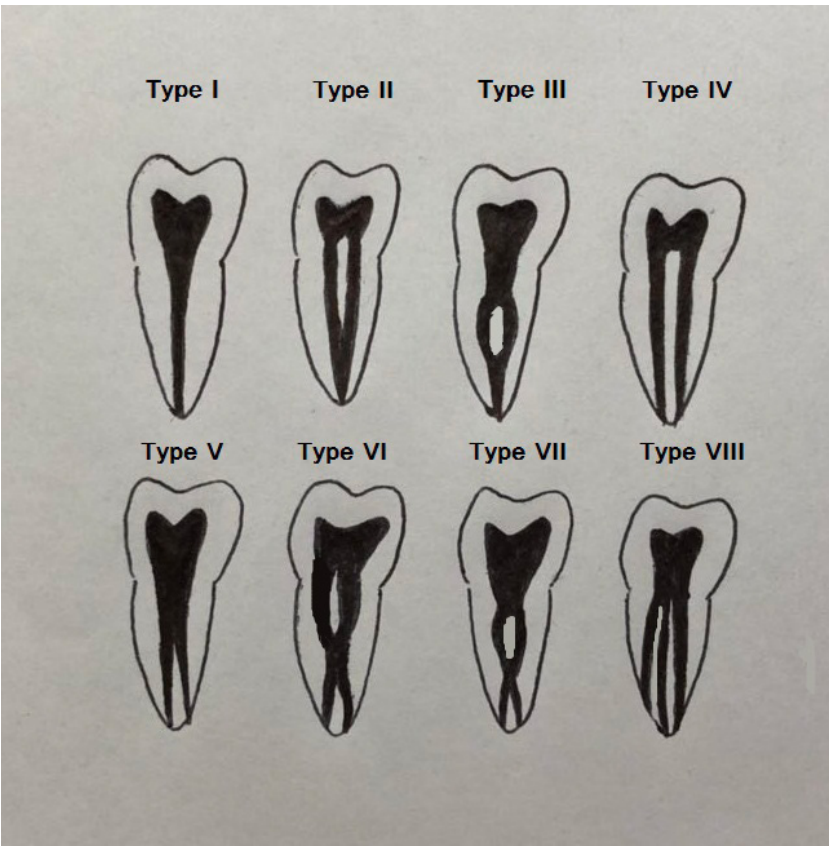

Fig. 2. Canal types according to Vertucci classification

Other evaluated items included the presence of maxillary second molars with 2 palatal roots (Fig. 1C), presence of $\mathrm{C}$-shaped canals in the maxillary and mandibular second molars (Fig. 3), and presence of a second mesiobuccal canal in the maxillary second molars (Fig. 4). Age and gender of the patients were recorded as well. One radiologist and 2 endodontists separately viewed the images twice within a 2-week interval. The data was analyzed using the IBM SPSS Statistics software v. 22 (IBM, Inc., Armonk, USA) via descriptive statistics, Fisher's exact test, the independent samples $t$-test, and the $\chi^{2}$ test.

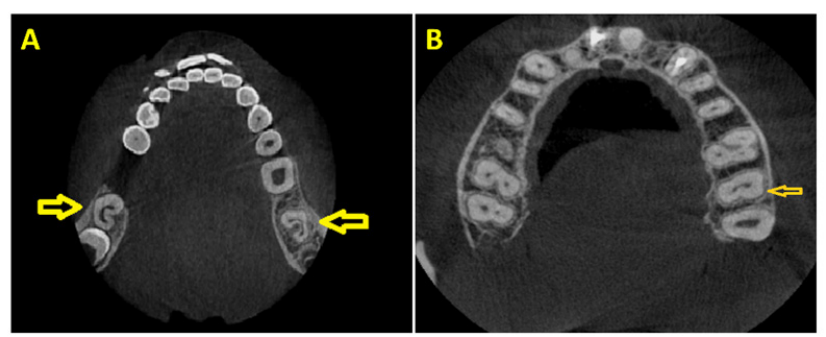

Fig. 3. A: Axial CBCT section of a C-shaped canal of a mandibular second molar; B: Axial CBCT section of a C-shaped canal of a maxillary second molar

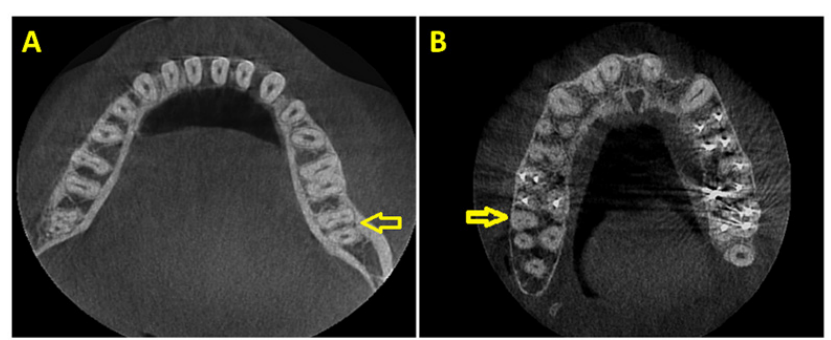

Fig. 4. A: Axial CBCT section of a mandibular second molar with 2 roots and 2 canals in the mesial root and 1 canal in the distal root; $\mathrm{B}$ : Axial CBCT section of a second mesiobuccal canal of a maxillary second molar

\section{Results}

A total of 502 CBCT scans of patients were evaluated, which belonged to 301 females $(60 \%)$ of a mean age of $38.04 \pm 12.73$ years and 201 males $(40 \%)$ of a mean age of $40.60 \pm 12.58$ years. The overall mean age of the patients was $39.06 \pm 12.72$ years. The intra-observer and inter-observer agreements were found to be $96 \%$ and $89 \%$, respectively, which indicated high agreement. A total of 1,082 second molars (447 mandibular and 635 maxillary second molars) were evaluated. Table 1 presents the frequency distribution of different types of roots. Tables 2 and 3 show the frequency of different types of canals in different roots according to the Vertucci classification. Tables 4 and 5 present the number of canals in the roots of the mandibular and maxillary second molars. Of 635 maxillary second molars, only 2 had 4 roots and showed a second palatal root. Of 447 mandibular second molars, 41 (9.2\%) had C-shaped canals. Specifically, 29 females (10.5\%) and 12 males (7.0\%) had C-shaped canals in their mandibular second molars. According to Fisher's exact test, the difference between males and females in the prevalence of C-shaped canals in the mandibular second molars was not significant $(p=0.240)$. The mean age of the patients with $\mathrm{C}$-shaped canals of the mandibular second molars was $34.17 \pm 13.83$ years and of those without C-shaped canals in the mandibular second molars $-36.84 \pm 12.05$ years. According to the independent samples $t$-test, this difference was not significant (Tables 6,7). An assessment of the maxillary second molars revealed only 1 case of a C-shaped canal.

Of 635 maxillary second molars, 558 had 1 mesiobuccal root, out of which 120 had a second mesiobuccal canal. The $X^{2}$ test showed a significant correlation between the prevalence of maxillary second molars with a second mesiobuccal canal and gender $(p=0.002$; Table 8$)$.

The independent samples $t$-test showed a significant correlation between the mean age of patients and prevalence of maxillary second molars with 2 canals in the mesiobuccal root ( $p=0.001$; Table 9$)$.

Table 1. Frequency distribution of the root variations in the mandibular and maxillary second molars

\begin{tabular}{|c|c|c|c|c|c|c|}
\hline \multirow[b]{2}{*}{$\begin{array}{l}\text { Number } \\
\text { of roots }\end{array}$} & \multicolumn{2}{|c|}{ Mandible } & \multicolumn{2}{|c|}{ Maxilla } & \multicolumn{2}{|c|}{ Total } \\
\hline & $\begin{array}{l}\text { number } \\
\text { of teeth }\end{array}$ & $\begin{array}{c}\text { percen- } \\
\text { tage } \\
{[\%]}\end{array}$ & $\begin{array}{l}\text { number } \\
\text { of teeth }\end{array}$ & $\begin{array}{c}\text { percen- } \\
\text { tage } \\
{[\%]}\end{array}$ & $\begin{array}{l}\text { number } \\
\text { of teeth }\end{array}$ & $\begin{array}{c}\text { percen- } \\
\text { tage } \\
{[\%]}\end{array}$ \\
\hline 1 root & 41 & 9.2 & 50 & 7.9 & 91 & 8.4 \\
\hline 2 roots & 397 & 88.8 & 27 & 4.2 & 424 & 39.2 \\
\hline 3 roots & 9 & 2.0 & 556 & 87.6 & 565 & 52.2 \\
\hline 4 roots & 0 & 0 & 2 & 0.3 & 2 & 0.2 \\
\hline Total & 447 & 100 & 635 & 100 & 1,082 & 100 \\
\hline
\end{tabular}


Table 2. Prevalence of Vertucci canal types for different roots in the mandibular second molars

\begin{tabular}{|c|c|c|c|c|c|c|c|}
\hline \multirow{2}{*}{ Root } & \multicolumn{7}{|c|}{ Vertucci type of canal } \\
\hline & I & ॥ & III & IV & V & VIII & Total \\
\hline Mesial & $65(16.0)$ & $222(54.7)$ & $0(0)$ & $116(28.6)$ & $3(0.7)$ & $0(0)$ & $406(100)$ \\
\hline Distal & $396(97.54)$ & $5(1.23)$ & $0(0)$ & $5(1.23)$ & $0(0)$ & $0(0)$ & $406(100)$ \\
\hline Additional root in mandibular second molar & $9(100)$ & $0(0)$ & $0(0)$ & $0(0)$ & $0(0)$ & $0(0)$ & $9(100)$ \\
\hline Single-rooted mandibular second molar & $10(24.4)$ & $14(34.1)$ & $3(7.3)$ & $7(17.1)$ & $2(4.9)$ & $5(12.2)$ & $41(100)$ \\
\hline Total & $480(55.7)$ & $241(27.9)$ & $3(0.34)$ & $128(14.9)$ & $5(0.58)$ & $5(0.58)$ & $862(100)$ \\
\hline
\end{tabular}

Data presented as number (percentage).

Table 3. Prevalence of Vertucci canal types for different roots in the maxillary second molars

\begin{tabular}{|c|c|c|c|c|c|c|c|}
\hline \multirow{2}{*}{ Root } & \multicolumn{7}{|c|}{ Vertucci type of canal } \\
\hline & I & II & III & IV & V & VIII & Total \\
\hline Palatal & $580(99.1)$ & $5(0.9)$ & $0(0)$ & $0(0.0)$ & $0(0)$ & $0(0)$ & $585(100)$ \\
\hline Mesiobuccal & $438(78.5)$ & $101(18.1)$ & $0(0)$ & $19(3.4)$ & $0(0)$ & $0(0)$ & $558(100)$ \\
\hline Distobuccal & $556(99.6)$ & $0(0)$ & $0(0)$ & $1(0.2)$ & $1(0.2)$ & $0(0)$ & $558(100)$ \\
\hline Additional root in maxillary second molar & $2(100)$ & $0(0)$ & $0(0)$ & $0(0)$ & $0(0)$ & $0(0)$ & $2(100)$ \\
\hline Single-rooted maxillary second molar & $14(28.0)$ & $9(18.0)$ & $0(0)$ & $14(28.0)$ & $5(10.0)$ & $8(16.0)$ & $50(100)$ \\
\hline Buccal root of double-rooted maxillary second molar & $10(37.0)$ & $8(29.7)$ & $0(0)$ & $9(33.3)$ & $0(0)$ & $0(0)$ & $27(100)$ \\
\hline Total & $1,600(89.9)$ & $123(6.9)$ & $0(0)$ & $43(2.41)$ & $6(0.34)$ & $8(0.45)$ & $1,780(100)$ \\
\hline
\end{tabular}

Data presented as number (percentage).

Table 4. Frequency of different number of canals in different roots of the mandibular second molars

\begin{tabular}{|c|c|c|c|c|}
\hline Root & 1 canal & 2 canals & 3 canals & Total \\
\hline Mesial & $65(16.0)$ & $341(84.0)$ & $0(0)$ & $406(100)$ \\
\hline Distal & $396(97.5)$ & $10(2.5)$ & $0(0)$ & $406(100)$ \\
\hline Additional root in mandibular second molar & $9(100)$ & $0(0)$ & $0(0)$ & $9(100)$ \\
\hline Single-rooted mandibular second molar & $10(24.4)$ & $26(63.4)$ & $5(12.2)$ & $41(100)$ \\
\hline Total & $480(55.7)$ & $377(43.7)$ & $5(0.6)$ & $862(100)$ \\
\hline
\end{tabular}

Data presented as number (percentage).

Table 5. Frequency of different number of canals in different roots of the maxillary second molars

\begin{tabular}{|c|c|c|c|c|}
\hline Root & 1 canal & 2 canals & 3 canals & Total \\
\hline Palatal & $580(99.1)$ & $5(0.9)$ & $0(0)$ & $585(100)$ \\
\hline Mesiobuccal & $438(78.5)$ & $120(21.5)$ & $0(0)$ & $558(100)$ \\
\hline Distobuccal & $556(99.6)$ & $2(0.4)$ & $0(0)$ & $558(100)$ \\
\hline Additional root in maxillary second molar & $2(100)$ & $0(0)$ & $0(0)$ & $2(100)$ \\
\hline Single-rooted maxillary second molar & $15(30.0)$ & $27(54.0)$ & $8(16.0)$ & $50(100)$ \\
\hline Buccal root of double-rooted maxillary second molar & $10(37.0)$ & $17(63.0)$ & $0(0)$ & $27(100)$ \\
\hline Total & $1,601(89.95)$ & $171(9.6)$ & $8(0.45)$ & $1,780(100)$ \\
\hline
\end{tabular}

Data presented as number (percentage).

Table 6. Correlation of the prevalence of C-shaped canals and the gender of patients (Fisher's exact test)

\begin{tabular}{|l|c|c|c|c|c|c|}
\multirow{2}{*}{ C-shaped canal } & \multicolumn{2}{|c|}{ Females } & \multicolumn{2}{c|}{ Males } & \multicolumn{2}{c}{ Total } \\
\cline { 2 - 6 } & number of teeth & percentage [\%] & number of teeth & percentage [\%] & number of teeth & percentage [\%] \\
\hline Absence of C-shaped canal & 246 & 89.5 & 160 & 93.0 & 406 \\
Presence of C-shaped canal & 29 & 10.5 & 12 & 7.0 & 41 \\
Total & 275 & 100 & 172 & 100 & 4.8 \\
\hline
\end{tabular}


Table 7. Correlation of the prevalence of C-shaped canals and the age of patients (the independent samples t-test)

\begin{tabular}{|l|c|cc|c|}
\hline \multicolumn{1}{|c|}{ C-shaped canal } & Number of teeth & Mean age [years] & SD & MD \\
\hline Absence of C-shaped canal & 406 & 36.84 & 12.05 & 0.598 \\
Presence of C-shaped canal & 41 & 34.17 & 13.83 & 0.182 \\
\hline
\end{tabular}

SD - standard deviation; $M D$ - mean deviation.

Table 8. Prevalence of a second mesiobuccal canal in the maxillary second molars and its correlation with gender (the $x^{2}$ test)

\begin{tabular}{|c|c|c|c|c|c|c|c|}
\hline \multirow{2}{*}{$\begin{array}{l}\text { Type of canal in } \\
\text { mesiobuccal root }\end{array}$} & \multicolumn{2}{|c|}{ Females } & \multicolumn{2}{|c|}{ Males } & \multicolumn{2}{|c|}{ Total } & \multirow{2}{*}{$p$-value } \\
\hline & number of teeth & percentage [\%] & number of teeth & percentage [\%] & number of teeth & percentage [\%] & \\
\hline Single-canal mesiobuccal root & 273 & 83.0 & 165 & 72.1 & 438 & 78.5 & \\
\hline Double-canal mesiobuccal root & 56 & 17.0 & 64 & 27.9 & 120 & 21.5 & 0.002 \\
\hline Total & 329 & 100 & 229 & 100 & 558 & 100 & \\
\hline
\end{tabular}

Table 9. Correlation of the prevalence of C-shaped canals and the age of patients (the independent samples $t$-test)

\begin{tabular}{|l|c|c|c|c|}
\multicolumn{1}{|c|}{ Type of canal in mesiobuccal root } & Number of teeth & Mean age [years] & SD & MD \\
\hline Single-canal mesiobuccal root & 438 & 37.73 & 13.01 & 0.621 \\
\hline Double-canal mesiobuccal root & 120 & 33.50 & 11.11 & 1.010 \\
\hline
\end{tabular}

\section{Discussion}

In this study, 502 CBCT scans of patients were evaluated. A total of 1,082 second molars, including 447 mandibular and 635 maxillary second molars, were assessed. The results showed that the prevalence of single-rooted, 2-rooted, 3-rooted, and 4-routed maxillary second molars was $7.9 \%, 4.2 \%, 87.6 \%$, and $0.3 \%$, respectively. Vertucci type I was the most common canal type in the palatal, mesiobuccal, distobuccal, and additional roots of the maxillary second molars. One single canal was the most common canal type in the palatal $(99.1 \%)$, mesiobuccal (78.5\%) and distobuccal (99.6\%) roots of the maxillary second molars.

Neelakantan et al. showed that of maxillary second molars, $0.9 \%$ were single-rooted, $5.8 \%$ were 2 -rooted, $93.1 \%$ were 3 -rooted, and $0.9 \%$ were 4 -rooted. ${ }^{10}$ Similarly in our study, maxillary second molars with 3 roots had the highest and those with 4 roots had the lowest frequency. In line with our findings, $\mathrm{Ng}$ et al. observed in their study that all maxillary second molars had 3 separate roots. ${ }^{11}$ All palatal roots $(100 \%)$ and the majority of the distobuccal roots (96\%) had 1 single canal and were Vertucci type I. A mesiobuccal root with 2 canals was observed in $68 \%, 49 \%$ and $39 \%$ of first, second and third molars, respectively. Vertucci types II and IV were the most common canal morphology in the mesiobuccal root. ${ }^{11}$

The current findings, compared to other studies, showed that the maxillary second molar root and canal morphology had high variability in the Iranian population and its anatomical variants were different from those in other populations. In the present study, $78.5 \%$ of the maxillary second molars had single-canal mesiobuccal roots, which were Vertucci type I, and 120 (21.5\%) mesiobuccal roots had a second mesiobuccal canal, out of which $18.1 \%$ were Vertucci type II and $3.4 \%$ were Vertucci type IV. Similarly, Sadeghi and Sadr reported that $74 \%$ of the mesiobuccal roots of second molars were Vertucci type $\mathrm{I}^{12}$ whereas Kim et al. reported the prevalence of a second mesiobuccal canal in the mesiobuccal roots of second molars to be $34.39 \% .{ }^{13}$ This value was $42.2 \%$ in a study by Lee et al. ${ }^{14}$ Alavi et al. and $\mathrm{Ng}$ et al. reported the presence of additional canals in the mesiobuccal root in $56 \%$ and $49 \%$ of second molars, respectively. ${ }^{15,11}$ This rate was $58 \%$ in a study by Shalabi et al. ${ }^{16}$

According to previous studies, the prevalence of a second mesiobuccal canal in the mesiobuccal root of maxillary second molars is significantly correlated with age, gender and position of the tooth. ${ }^{13,17,18}$ The current study also showed a significant correlation between the age and sex of patients and the occurrence of a second mesiobuccal canal in the maxillary second molars, i.e., the prevalence of a second mesiobuccal canal in the maxillary second molars was higher in males and in younger patients.

Gomes et al. used CBCT and demonstrated that $68.23 \%$ of maxillary molars had a second mesiobuccal canal, and a significant correlation existed between the prevalence of a second mesiobuccal canal and the age and gender of patients. ${ }^{17}$ The prevalence of a second mesiobuccal canal was higher in younger patients irrespective of gender. Conversely, another study reported higher prevalence of a second mesiobuccal canal in older individuals. ${ }^{19}$

Knowledge of the morphology of the roots and canals of the mandibular second molars in different races and populations is imperative. The current results revealed that the prevalence of mandibular second molars with one, 2 or 3 roots was $9.2 \%, 88.8 \%$ and $2.0 \%$, respectively. 
The most common canal type in the mesial (54.7\%) and distal $(97.5 \%)$ roots of the mandibular second molars was Vertucci type II and I, respectively. The most frequent number of canals in the mesial (84.0\%) and distal $(97.5 \%)$ roots of the mandibular second molars was 2 canals and 1 single canal, respectively. In a study by Gulabivala et al., $58 \%$ of second molars had 2 roots, and Vertucci types II and IV were the most common canal types in the mesial root. ${ }^{20}$

In a study by Zhang et al., $76 \%$ of second molars had 2 roots, $22 \%$ had 1 root and $2 \%$ had 3 roots. ${ }^{21}$ Their results are in agreement with our findings. Moreover, $97 \%$ of the distal roots and $42 \%$ of the mesial roots were Vertucci type I, $65 \%$ of the mesial roots had 2 canals and were Vertucci type IV, and 27\% were Vertucci type V. Compared to our study, $84.0 \%$ of the mesial roots had 2 canals, out of which $54.4 \%$ were Vertucci type II and $28.6 \%$ were Vertucci type IV.

Our findings, compared to those of the above-mentioned studies and the results of Ahmed et al. ${ }^{22}$ and Weine et al., ${ }^{23}$ indicated that the frequency of mandibular second molars with 2 roots in our study was higher than the rate reported in other populations, and the anatomical and morphological variations of the second molars in our study were different from those in other populations.

The current results indicated that of 447 mandibular second molars, 9.2\% had C-shaped canals. No significant correlation was noted between the prevalence of C-shaped canals in the mandibular second molars and age or gender of the patients. The prevalence of $\mathrm{C}$-shaped canals was reported to be $13.8 \%$ in a study by Ashraf and Grayeli and $3 \%$ in a study by Nourmandipour and Nasiri. ${ }^{24,25}$ In a study by Weine et al., the prevalence of C-shaped canals in Caucasians was reported to be $7.2 \%,{ }^{23}$ while this rate was $6.7 \%$ in the United States. ${ }^{26}$ The prevalence of C-shaped canals in the mandibular second molars of the Chinese, Taiwanese and Burmese populations ranges from $22.4 \%$ to $32.5 \%$, which is largely different from the value found in our study. ${ }^{20}$ This difference may be attributed to racial differences as well as different clinical criteria used for the detection of C-shaped canals. ${ }^{20,26}$ On the other hand, our findings, similar to those of previous studies, confirmed the absence of a significant correlation between the prevalence of $\mathrm{C}$-shaped canals and age or sex of the patients. ${ }^{27-29}$ The use of CBCT and the large sample size were among the strengths of this study, which increased the accuracy of the results.

\section{Conclusions}

The results of this study revealed higher prevalence of 2-rooted mandibular second molars and 3-rooted maxillary second molars in our study population. Considering the $9.2 \%$ prevalence of $C$-shaped canals in our study population, dental clinicians should pay utmost attention to detecting such canals in order to increase the success rate of root canal treatment. Failure in detection and treatment of a second mesiobuccal canal decreases the longterm success rate of endodontic treatment. Cone-beam computer tomography can be used as a non-invasive imaging modality with high accuracy for the detection of additional roots and canals, including $\mathrm{C}$-shaped canals. It provides clinicians with valuable information about the root canal anatomy.

\section{ORCID iDs}

Zakiyeh Donyavi (D) https://orcid.org/0000-0003-0362-2107 Abbas Shokri (D) https://orcid.org/0000-0002-3434-3672 Elham Khoshbin (D) https://orcid.org/0000-0002-5068-8080 Maryam Khalili (D) https://orcid.org/0000-0002-0122-4650 Javad Faradmali (D) https://orcid.org/0000-0001-5514-3584

\section{References}

1. Monika, Dhawan R, Dhawan S, Mehta P. Analysis of root canal anatomy and morphological variations of maxillary $1^{\text {st }}$ molar by different methods - an in vitro study. Endodontolgy. 2014;26(2):279-285

2. Al-Qudah AA, Awawdeh LA. Root and canal morphology of mandibular first and second molar teeth in a Jordanian population. Int Endod J. 2009;42(9):775-784.

3. Mărgărit $\mathrm{R}$, Andrei $\mathrm{OC}$. Anatomical variations of mandibular first molar and their implications in endodontic treatment. Rom J Morphol Embryol. 2011;52(4):1389-1392.

4. Sobhani Mohhsen A, Razmi H, Sadegh M. Evaluation of anatomy and morphology of human mandibular premolar teeth by cone-beam computed tomography in Iranian population. Journal of Dental Science. 2013;26(3):203-210.

5. Ravanshad S, Nabavizade MR. Endodontic treatment of a mandibular second molar with two mesial roots: Report of a case. Iran EndodJ. 2008;3(4):137-140.

6. Vertucci FJ. Root canal anatomy of the human permanent teeth. Oral Surg Oral Med Oral Pathol. 1984;58(5):589-599.

7. Cotton TP, Geisler TM, Holden DT, Schwartz SA, Schindler WG. Endodontic applications of cone-beam volumetric tomography. J Endod. 2007;33(9):1121-1132.

8. Celikten B, Tufenkci P, Aksoy U, et al. Cone beam CT evaluation of mandibular molar root canal morphology in a Turkish Cypriot population. Clin Oral Investig. 2016;20(8):2221-2226.

9. Torres A, Jacobs R, Lambrechts P, et al. Characterization of mandibular molar root and canal morphology using cone beam computed tomography and its variability in Belgian and Chilean population samples. Imaging Sci Dent. 2015;45(2):95-101.

10. Neelakantan P, Subbarao C, Ahuja R, Subbarao CV, Gutmann JL. Cone-beam computed tomography study of root and canal morphology of maxillary first and second molars in an Indian population. J Endod. 2010;36(10):1622-1627.

11. Ng YL, Aung T, Alavi A, Gulabivala K. Root and canal morphology of Burmese maxillary molars. Int Endod J. 2001;34(8):620-630.

12. Sadeghi M, Sadr LM. An in vitro study on root canal anatomy in maxillary molars. Maj Dand. 2004;16:14-21.

13. Kim Y, Lee SJ, Woo J. Morphology of maxillary first and second molars analyzed by cone-beam computed tomography in a Korean population: Variations in the number of roots and canals and the incidence of fusion. J Endod. 2012;38(8):1063-1068.

14. Lee JH, Kim KD, Lee JK, et al. Mesiobuccal root canal anatomy of Korean maxillary first and second molars by cone-beam computed tomography. Oral Surg Oral Med Oral Pathol Oral Radiol Endod. 2011;111(6):785-791.

15. Alavi AM, Opasanon A, Ng YL, Gulabivala K. Root and canal morphology of Thai maxillary molars. Int Endod J. 2002;35(5):478-485.

16. al Shalabi RM, Omer OE, Glennon J, Jennings M, Claffey NM. Root canal anatomy of maxillary first and second permanent molars. Int Endod J. 2000;33(5):405-414. 
17. Gomes Alves CR, Martins Marques M, Stella Moreira M, Harumi Miyagi de Cara SP, Silveira Bueno CE, Lascala CÂ. Second mesiobuccal root canal of maxillary first molars in a Brazilian population in high-resolution cone-beam computed tomography. Iran Endod J. 2018;13(1):71-77.

18. Wang $H, C i B$, Zhang $X$, et al. Analysis of patients with a second canal in mesiobuccal root of maxillary molars in Southern China: A retrospective study. Int J Clin Exp Med. 2017;10(9):13678-13688.

19. Guo J, Vahidnia A, Sedghizadeh $P$, Enciso R. Evaluation of root and canal morphology of maxillary permanent first molars in a North American population by cone-beam computed tomography. J Endod. 2014;40(5):635-639.

20. Gulabivala K, Aung TH, Alavi A, Ng YL. Root and canal morphology of Burmese mandibular molars. Int Endod J. 2001;34(5):359-370.

21. Zhang $R$, Wang $H$, Tian $Y Y, Y u X, H u T$, Dummer PM. Use of conebeam computed tomography to evaluate root and canal morphology of mandibular molars in Chinese individuals. Int Endod J. 2011;44(11):990-999.

22. Ahmed HA, Abu-Bakr NH, Yahia NA, Ibrahim YE. Root and canal morphology of permanent mandibular molars in a Sudanese population. Int Endod J. 2007;40(10):766-771.

23. Weine FS, Pasiewicz RA, Rice RT. Canal configuration of the mandibular second molar using a clinically oriented in vitro method. J Endod. 1988;14(5):207-213.

24. Ashraf $H$, Grayeli M. Determine frequency and anatomic form of the C-shaped canals in mandibular second molars. J Dent Sch. 2004;21(21):441-446.

25. Nourmandipour M, Nasiri M. Prevalence of C-shaped mandibular second molars in Zahedan. Zahedan Journal of Research in Medical Sciences (Tabib-E-Shargh). 2008;9(4):313-318.

26. Weine FS; Members of the Arizona Endodontic Association. The C-shaped mandibular second molar: Incidence and other considerations. J Endod. 1998;24(5):372-375.

27. Ladeira DB, Cruz AD, Freitas DQ, Almeida SM. Prevalence of C-shaped root canal in a Brazilian subpopulation: A cone-beam computed tomography analysis. Braz Oral Res. 2014;28:39-45.

28. Sartaj M, Sangra A, Farooq R, Rashid A, Ahmad F. C-shaped configuration of the root canal system of mandibular second molar: A case report. Int J Appl Dent Sci. 2017;3(1):98-100.

29. Zheng Q, Zhang L, Zhou X, et al. C-shaped root canal system in mandibular second molars in a Chinese population evaluated by conebeam computed tomography. Int Endod J. 2011;44(9):857-862. 